budgets to a pan-European agency without resistance. Nevertheless, the demands and complaints from the scientific community have already caused reactions among European officials. Ernst-Ludwig Winnacker, President of the Deutsche Forschungsgemeinschaft, Germany's largest funding agency, pointed out that many European agencies already contribute part of their budgets to trans-national research and/or allow scientists to spend their grant in another country. "In addition to the EU, there is a virtual ERC already in existence, which is, of course, deeply founded in the national research councils," Winnacker said. Nevertheless, the constitutional basis for any trans-national system is missing, and needs to be established in parallel with the ERC. "We eventually need a legal structure," Winnacker said. This, as he and others pointed out, would be the European Constitution that is now being discussed in the convention headed by Valéry Giscard $d^{\prime}$ Estaing, the former French President. In fact, the prospects for science and research at the proposal stage look good. The Constitution would replace the Treaty of Amsterdam, the current legal basis for the EU's business, which makes basic research the responsibility of national governments. Consequently, many participants felt a need to lobby the European Parliament and their national governments to ensure that science remains prominent during the Constitution's final formulation.

\section{... [scientists] believe the ERC to be the magic cure for all the ailments now plaguing science and research in Europe}

It is also questionable as to whether the EC would be willing to take a chance and give scientists a lot of money, along with the freedom to decide what to do with it. Peter Kind (Fig. 3), Director of Directorate B of the EC's Directorate-General for Research, sent out a clear message at the meeting: Do not count on the EU to help you, and if you want to create an ERC, it had better be different to what is already in place, and give 'added value' to European science and research. At the same time, however, the EC seems to have already made up its mind; at least, that would explain why they recently gave $€ 20$ million to the European Science Foundation (ESF) to 'catal$y^{\prime} e^{\prime}$ the Eurohorcs-which represent the
"Nothing is more powerful than an idea whose time has come"

national funding agencies-in what could be seen as a first step towards an ERC. Lost in this entanglement of 'Eurorganizations' and 'E-cronyms', however, would be accountability and independence, as some criticized in private conversations. An ERC run by the Eurohorcs and the ESF, being the platform for the national agencies, would not necessarily be independent of national influences and wishes, which, again, are not necessarily independent of politicians. It would also fail to meet one of the main demands of the scientific community, namely that the ERC should be a new scheme, established and run mostly by scientists.

And industry is not prepared to participate either. "Do not expect any support from the European life science industry, because it is not possible," Horst Domdey from BioM, a service company for biotech start-ups, in Munich, Germany, said. "The pharmaceuti- cal industry is not able to fund science at arm's length," Hans van den Berg, from the Animal Cell Technology Industry Platform, concurred. So, the money needs to come from the governments, who have made their commitment to the $3 \%$ goal. But, as Rolf Tarrach from the Eurohorcs pointed out, they tend not to be accountable, particularly as those politicians who signed the Barcelona statement are unlikely to be in power in 2010. For him, however, this is just one more argument for an ERC: "We still have to do it, precisely because if we do it properly, an ERC will raise some new money." But others felt that politicians also have to be held responsible for their promises. As Connerade pointed out, if the heads of state, "with an arrogant stroke of the pen," sign a commitment, it is their task to fulfil it: "We should turn the question back on them-if they sign the paper, they should tell us where the money comes from."

\section{Holger Breithaupt}

doi:10.1038/sj.embr.embor814

\title{
The ethics of innovation
}

\author{
Should innovative surgery be exempt from clinical trials and regulations?
}

$\mathrm{L}$ ast summer, researchers from the Veterans Affairs Medical Center (Houston, TX, USA) published the startling results of a placebo-controlled study of arthroscopic surgery. At no point, they reported, did the patients in the surgery group report less pain or better functioning of the knee than the patients who received placebo surgery-just cutting the knee without further intervention-according to lead investigator J. Bruce Moseley (Moseley et al., 2002). Scientists have long known about the placebo effects of medical treatments, so the outcome of the study is not necessarily a revelation. What is more surprising is that this type of arthroscopic surgery has never been tested before in a placebo-controlled study to determine its merits, as is the case for many other forms of surgery and surgical techniques. It raises new and serious questions about the ethics and efficiency of surgical practice and other forms of medical intervention, which, unlike new drugs and medical devices, are not subject to rigorous clinical trials.
"Historically, surgical research has not been held to the same scientific, regulatory and ethical standards as other medical research," said Dorothy Vawter, a bioethicist at the University of Minnesota's Center for Bioethics (Minneapolis, MN, USA). There is a growing debate about whether more control is needed over new surgical innovations. At present, only $\sim 7 \%$ of surgical investigators use a randomized-study design of any type, according to a report in The Lancet (1999). Another study found that, during the previous four decades, only $10-20 \%$ of surgical techniques have undergone any clinical trials (Salzman, 1985). "An increasing emphasis on technological innovation and the practice of describing 'new' surgeries to the newspapers before they are formally tested, makes the need for more thoughtful dialogue about what constitutes human research and how to best protect patients' rights even more urgent," commented ophthalmologist and pathologist Curtis Margo in the Journal of Medical Ethics (Margo, 2001). "The distinction between clinical practice and surgical 
research may seem trivial, but this distinction can become a complex issue when innovative surgeries are substituted for standard care without patient knowledge," he said.

Paediatrician and bioethicist Joel Frader, at Northwestern University's School of Medicine (Chicago, IL, USA), agrees that surgeons have a moral obligation to formally compare their preferred operations with alternative approaches. He cited, as an example, a retrospective study of lung transplantation in children with cystic fibrosis, which showed that drug treatments resulted in a better outcome. Had researchers tested the efficacy of lung transplantation against these treatments from the outset, better therapy could have been offered sooner to children. "Innovation in surgery proceeds very differently [than for drug and device development], with relatively few controlled clinical trials and almost no government regulations," he asserted. Instead, surgeons prefer to rely on case series, a type of study that tracks individual patients and records their outcomes, but does not compare the procedure with an alternative. Frader finds this approach problematic for two reasons: it cannot account for confounding variables, nor for substantial changes in the overall effectiveness of care. "As reported case series tend to favor any given intervention, multiple similar reports reinforce a possibly mistaken view that the surgery provides benefits," he wrote (Frader \& Flanagan-Klygis, 2001). "Once this happens, conducting definitive trials becomes increasingly difficult. Pressure to use the new technique builds, as does the impression that withholding the surgery now amounts to 'unethical' treatment, despite the lack of clear evidence for an operation's efficacy."

A $t$ the same time, the proliferation of experimental cell and gene therapies are slowly changing this view. This goes hand-in-hand with the rise of managed care in the USA and its demand for accountability, and with an increase in medical malpractice suits that have all contributed to greater scrutiny in medical practice. A national network of Institutional Review Boards (IRBs) has been created under the auspices of the US Office for Human Research Protection, to protect participants in human research, as well as the researchers themselves. The family of James Quinn, the fifth recipient of the Abiocor (Danvers, MA, USA) artificial heart in a formal clinical trial, and who died in 2002, filed a lawsuit maintaining that he was improperly informed-under a

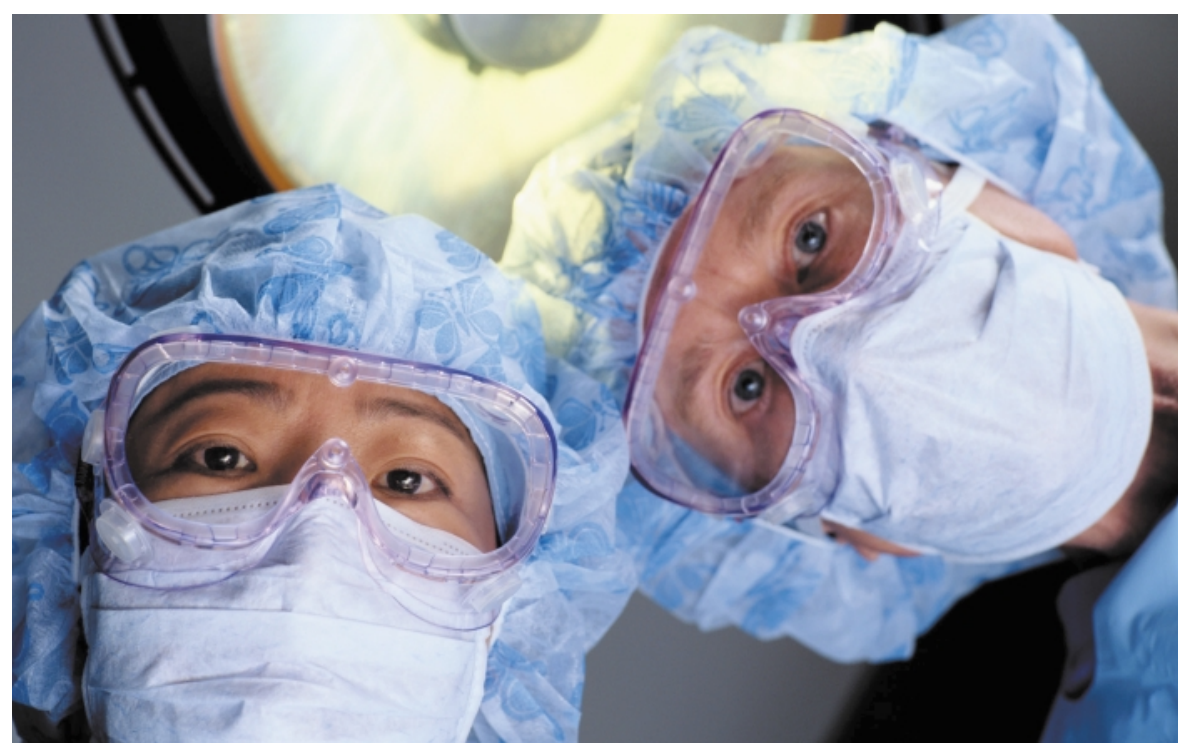

therapeutic misconception - that the heart could prolong and increase his quality of life. What is unusual here is that Abiocor had set up the first blind trust to fund patient advocates, who could represent the patients but not give them recommendations or advice. No one involved in the trial was allowed to own stock in the company. The head of the patient representative group, Haavi Morreim, a bioethicist at the University of Kentucky (Louisville, KY, USA), noted that if such a safeguard could not reduce the chances of a patient feeling the need to sue, she did not know what would. She observed that such "litigation could drive surgeons into the arms of the IRBs."

But bioethicist George Agich, of the Cleveland Clinic Foundation (OH, USA), disagrees with the call for more control over surgical innovation by IRBs, or others. He maintains that surgery is different from medicine and should be treated as such, and we should not require it to 'live' with the same safeguards that apply to drug and device development. Agich uses the example of coronary artery bypass graft (CABG) development to show that surgery does not fit the "regulatory ethics paradigm", which holds that IRBs are the best mechanism for the protection of human subjects. "CABG was problem driven, rather than developed from a rigid protocol," he said. "CABG developed from an emergent and fluid understanding of the disease process and mechanisms." Improvement came simultaneously from many areas, including anaesthesia, heart-lung bypass machines and surgical techniques. It was developed in response to patients' needs and new surgical opportunities, which depended on a high level of skill and quality of judgement on the part of the whole medical team. Agich believes that a "surgical innovation model" such as this is acceptable because it focuses on patients, is justified through internal processes and is clinically driven.

Nevertheless, the question of whether surgical techniques should undergo formal testing in a clinical trial creates problems of its own, particularly about the kind of test to use. The gold standard for drug approval is the double-blind, placebo-controlled study, and this may not be easily applicable to surgery. "Today, there is disagreement among neuroscientists about which research paradigms [...] are appropriate for surgical research on deep brain stimulation [DBS] and cellular implants in persons with PD [Parkinson's disease]," said Vawter. "Since surgical research of DBS invokes two different types of paradigms, namely, surgical research paradigms and FDA [the Food and Drug Administration]'s research paradigm for significant risk medical devices, the central ethical and policy challenge is whether one of these research paradigms should take precedence, or whether it is necessary to craft an accommodation of paradigms or even a novel paradigm," she commented at last year's meeting of the American Society for Bioethics and Humanities in Baltimore (MD, USA). Vawter believes that the risks of placebo surgery are justified by the high rate

\section{...during the past four decades, only $10-20 \%$ of surgical techniques have undergone any clinical trials}




\section{“...currently, there is greater oversight protection in place for laboratory animals than there is for testing innovative surgeries in humans"}

of placebo response to both surgery and medication among Parkinson's patients. However, Ruth Macklin, a bioethicist at the Albert Einstein College of Medicine (Bronx, NY, USA) disagrees, finding placebo-controlled surgery unacceptable because it does not minimize the risk of harm, and has no benefit to the patient.

A part from the question of the ethics of placebo surgery, a key issue in the debate is whether surgeons can regulate themselves and their peers. David Cronin, J. Michael Millis and Mark Siegler, from the University of Chicago (IL, USA), called for outside regulation to be put in place (Cronin et al., 2001). In their article, entitled 'Transplantation of liver grafts from living donors into adults-too much, too soon', they explain how liver-graft transplantation in adults developed from a highrisk experimental technique into a mainstream method. Liver-graft transplantation, originally carried out in children, was not tested for efficacy before it became a widely accepted practice as an extension to the procedure in children. They wrote that "Many key aspects of liver transplantation in adults with the use of grafts from living donors remain unclear; the same is not true of the procedure performed in children." But liver-graft transplantation in adults, which is seemingly market driven, has not been proven to be safe and effective. "The rapid proliferation of programs that perform transplantation into adults with the use of grafts from living donors is alarming for an innovative, non-standardised operation that places two people, one of whom is healthy, at risk," they criticize. For that reason, surgical standards should be higher than for a cadaver organ transplant, as well as the standard of informed consent, they note. Most importantly, due to 'market' demands - patients' demands for the most cutting-edge treatment-the authors believe it is "unreasonable to expect that those already doing these transplantations in adults will self-regulate." Surgical specialty societies have tried previously to establish certain criteria, but realistically they lack 'clout'. The Chicago researchers thus call for government and health insurers to oversee the field "in the absence of professional self-regulation," and warn that, unless professional self-regulation for other innovative surgical procedures improves, government regulation may not be restricted to innovative liver transplants.

S urgeons in the USA are still often characterized, not entirely negatively, as 'cowboys' - individuals who function autonomously, with a good deal of power, and who are subject to few controls. Not coincidentally, then, do Angelique Reitsma and Jonathan Moreno of the Center for Bioethics at the University of Virginia (Charlottesville, VA, USA) call innovative surgery "the last frontier". "Experimental surgery appears to remain virtually rule-free $[\ldots]$ and the existing guidelines and regulations appear insufficient to meet the challenge of innovative surgery," they wrote (Reitsma \& Moreno, 2002). Their study analysed whether surgeons knew about federal requirements for, and the role of local IRBs in, the process of clinical research. Reitsma and Moreno sent anonymous questionnaires to 59 surgical teams that carried out innovative surgery between 1992 and 2000. Of the 21 responses they received, 14 confirmed that their work was research, but only 6 had previously sought IRB review. Only seven mentioned the innovative nature of their technique in the informed consent form. Interestingly, although seven said they were familiar with the Office for Human Research Protection's definitions of 'research' and 'human subject', the others maintained that government regulations for the protection of human subjects in innovative surgery were not appropriate. Reitsma and Moreno concluded that the current system of definitions and voluntary professional guidelines are inadequate for surgical innovation.

Their work is part of a larger study funded by the US National Institutes of Health to develop ethical recommendations for experimental surgery and for a curriculum to increase awareness of and compliance with ethical regulations. As part of this process, Reitsma and Moreno have convened a multidisciplinary group of experts to pinpoint exactly what should be considered innovation, and possible ways for it to be institutionalized. Reitsma pointed out that surgeons were the first to adopt informed consent forms after the Second World War, but, since then, forms for surgery do not often reflect the experimental nature of a procedure. While the American College of Surgeons were initially unenthusiastic, Reitsma said that they had come on board.

Margo acknowledged that the question of what is research and what is therapy is "contentious and threatening", noting that "currently, there is greater oversight protection in place for laboratory animals than there is for testing innovative surgeries in humans." He thinks that "informal research" is a throwback to paternalism in medicine, when doctors gave themselves the authority to judge what patients should and should not know about clinical experiments. Although informal research has filled a gap between the laboratory development of a procedure and its formal testing in humans, there are no mechanisms in place to develop the preliminary stages of surgical research in humans under a formal protocol, he said; once a case series is presented at a scientific meeting, or submitted for scientific review, "there is no turning back." If physicians continue to include all informal research under the rubric of clinical practice, then they risk losing public confidence, Margo fears. It not only undermines the doctor-patient relationship, but also muddies the medical literature and the news with bad science, he concluded. Protecting human subjects must trump the 'greater good' of scientific research.

\section{REFERENCES}

Baum, M. (1999) Planning surgical are: reflections on randomised controlled trials in surgery. Lancet, 353 (Suppl. 1), 3-6.

Cronin, D.C., Millis, J.M. \& Siegler, M. (2001) Transplantation of liver grafts from living donors into adults - too much, too soon. N. Engl. J. Med., 344, 1633-1637.

Frader, J.E. \& Flanagan-Klygis, E. (2001) Innovation and research in pediatric surgery. Semin. Pediatr. Surg., 10, 198-203.

Margo, C.E. (2001) When is surgery research? Towards an operational definition of human research. J. Med. Ethics, 27, 40-43.

Moseley, J.B., O'Malley, K., Petersen, N.J., Menke, T.J., Brody, B.A., Kuykendall, D.H., Hollingsworth, J.C., Ashton, C.M. \& Wray, N.P. (2002) A controlled trial of arthroscopic surgery for osteoarthritis of the knee. N. Engl. J. Med., 347, 81-88.

Reitsma, A.M. \& Moreno, J.D. (2002) Ethical regulations for innovative surgery: the last frontier? J. Am. Coll. Surg., 194, 792-801.

Salzman, E.W. (1985) Is surgery worthwhile? Arch. Surg., 120, 771-776.

\section{Vicki Brower}

doi:10.1038/sj.embor.embor815 